\title{
FORTUNA VARIA DE UN CHISTE GONGORINO
}

Conocido es el epitafio ingenioso y cruel con que Góngora remata en 1589 el primero de sus romances sobre Hero y Leandro ${ }^{1}$. Este epitafio, dictado por la desventurada Hero en el momento de precipitarse desde la torre sobre las rocas de la playa al ver ahogado a su Leandro, resume con burlesca concisión la tragedia de los infelices amantes:

"El Amor, como dos hueuos, quebrantó nuestras saludes: él fue passado por agua, io estrellada mi fin tuue"2.

La pareja de amantes clásicos, cuya historia, a fines del siglo XvI, ha hecho derramar tiernas lágrimas a tantos lectores y ha inspirado y seguirá inspirando tantos conmovidos sonetos y romances y poemas, queda ridiculizada y degradada con ese devastador símil culinario.

La fortuna del chiste de los huevos - aplicado unas veces, como en Góngora, a la historia de Hero y Leandro, y reelaborado otras veces en contextos diferentes- fue notablemente larga y nutrida, según trataré de mostrar en las páginas que siguen.

No fue Góngora, sin embargo, el primero que discurrió ese feliz juego de palabras. Antes de cultivarse sistemáticamente en la literatura española de la época barroca, el equívoco conceptista tenía ya una larga historia ${ }^{3}$. En 1574 se podía leer este cuentecillo recogido por Melchor de Santa Cruz en su Floresta:

1 Romance "Arrojóse el mancebito", publicado por primera vez en la Quarta y quinta parte de Flor de romances, recopilados por Sebastian Vélez de Gueuara, Burgos, 1592 , fols. $185 \mathrm{v}^{\circ}-187 \mathrm{v}^{\circ}$ (reeditada ahora por ANTONIo RonRfguez MoÑino, Las fuentes del Romancero general, Madrid, 1957, t. 4), de donde pasó a la Quinta parte del Romancero general de 1600 (ed. A. González Palencia, Madrid, 1947, núm. 345). Véase mi estudio "Los romances de Hero y Leandro", en el Libro jubilar de Alfonso Reyes, México, 1956, pp. ${ }^{15}$-16. $^{16}$

2. Obras poéticas de D. Luis de Góngora, ed. R. Foulché-Delbosc [y Alfonso Reyes], New York, 1921, t. 1, p. 122.

3 "Esta afición -dice Fernando Lázaro Carreter en su valioso estudio "Sobre la dificultad conceptista", EMP, 6 (1956), p. 369- parece una constante del gusto nacional; hallamos sus rastros en todos los escritores popularistas, desde Juan Ruiz, pasando por el Romancero, el Lazarillo, la Celestina, Juan del Encina..."; Henry R. Bershas, "Cardenales: the case history of a pun", $R P h, 9$ 
Mandó un señor a su criado que saliesse a ver el cielo si estaua estrellado, porque quería salir fuera. Como estuuiesse muy nublado, respondió: "Señor, no está estrellado, sino passado por agua"1.

Y probablemente don Luis Zapata no conocía el romance de Góngora cuando en su curiosísima Miscelánea contaba el "atrevi. miento sobrenatural" de cierto arrojado jinete, que hacía con su caballo una suerte muy peligrosa:

El pretal era angosto..., y por allí metía desde fuera el caballo; y al pasar... le hacía dar dentro en la puente un salto que, a errar un punto, ahogado primero y pasado por agua, fuera a parar en tan manifiesto peligro al infierno ${ }^{5}$.

("Ahogado y pasado por agua", como el joven nadador Leandro). Y el mismo Zapata nos transmite otra faceta del chiste cuando más adelante recuerda

aquello que acaesció a don Alonso de Aguilar, en Córdoba, que pidiendo al ayuntamiento una cosa leve, todos le dijeron que sí, que le servirían con gran voluntad por sí cada uno, y después todos juntos no hicieron nada, y ansí él después les dijo: "Señores, estrellados os beso las manos a cada uno, y en tortilla échoos todos a rodar"'6.

Exactamente la misma forma presenta el chiste en una poesía publicada en 1593 (un año después de imprimirse el romance de Góngora). Como en la anécdota de la Floresta, la imagen se refiere aquí al cielo:

De auerse Albano mudado no te as de espantar, Belilla; pues el cielo, si as mirado, a la noche está estrellado y a la mañana en tortilla?.

(1955-56), 23-26, historia de un chiste "conceptista" análogo al que aqui estudio, lo encuentra ya en un poeta del siglo xv, Pérez de Guzmán: "a mugeres baxas vi descalabradas, / sin mitra e anillo traer cardenales". (Su último ejemplo es de Jardiel Poncela).

${ }_{4}$ Floresta española (1574), por Melchor de SANTa Cruz de Dueñas, ed. Bibliófilos Españoles, Madrid, 1953, p. 94.

5 Miscelánea de Zapata, ed. P. de G[ayangos], Madrid, 1859 (Memorial histórico español, t. 11), pp. 119-120. (IQué falta hace una buena edición moderna de la Miscelánea! No cuento, por supuesto, la de I. Montiel, Madrid, 1949).

6 Ibid., p. 235. -Como en la Floresta de Melchor de Santa Cruz (o en Las seiscientas apotegmas de Juan Rufo y las demás recopilaciones de esa índole), abundan en la Miscelánea de don Luis los juegos de palabras y los chistes conceptistas. La mejor muestra de ese gusto es el capítulo intitulado "De un agradable monstruo" (pp. 177-180), obra de "autor incierto", cuya relación con el Monsiruo imaginado de Alonso de Ledesma no sé si se ha estudiado.

7 Estribillo de una composición del Ramillete de flores: Quarta, quinta 
Años después, el joven Mateo Vázquez de Leca, futuro secretario de la Inquisición, canónigo de Sevilla y arzobispo de Carmona, ridiculiza en un soneto los amores de Hero y Leandro, siguiendo las huellas de Góngora y copiando, con una leve modificación, el chiste de los huevos:

¡Cuerpo de Dios, Leandro enternecido!

¡Quánto mejor te fuera auer passado en varcos de la vez el mar salado, que no passar a nado desde Abido!

¿No te fuera mejor auer viuido y a pies enxutos tu muger gozado, y no llegar a Sesto resfriado en la primera noche de marido?

No son tan necios otros amadores, que passan a Triana de Seuilla todas las noches en varquetes nueuos ${ }^{8}$.

¡Buen aliño tuuieron tus amores: tú passado por agua, Hero en tortilla, y cenóse el diablo el par de hueuos! ${ }^{9}$

y sexta parte de Flor de romances nueuos, Lisboa, 1593, fol. $125 \mathrm{r}^{\circ}$ (reeditado por A. Rodríguez MoÑino, Las fuentes del Romancero general, t. 5); se lee también en la Sexta parte de Flor de romances nueuos, Toledo, 1594, fol. $70 \mathrm{v}^{\circ}$ (reeditada por el mismo Rodríguez Moñino, Las fuentes..., t. 8). La poesía pasó luego a la Sexta parte del Romancero general de 1600 (ed. cit., núm. 408).

8 Estos "varquetes nueuos" en que pasan cada noche los galanes de Sevilla a Triana bien se merecen una nota. Aparecen en no pocas seguidillas de fines del xvi y comienzos del xvn. He aquí una: "Salen de Seuilla / barquetes nueuos, / que de verde aya / lleuan los remos" "Les romancerillos de Pisa", RHi, 65, 1925 , 153 ss., núm. 79; también en uno de los "cartapacios salmantinos", BRAE, 1, 1914, p. 311). Otra: "Barcos enramados / van a Triana: / el primero de todos / me lleva el alma" (Lope de Vega, Amar, servir y esperar, II, AcadN, t. 3, p. $227 b$ ). Y otra: "Barcos de Sevilla / pasan a Triana, / porque da más gusto / la puente del agua" (Lope, Amar sin saber a quién, III, AcadN, t. 9, p. 312b; aquí, la seguidilla está asimilada a un romancillo). Hay muchas más. La seguidilla era, en ese momento, un género juvenil y pujante (y demasiado fácil).

9 Primera parte de las Flores de poetas ilustres de España, ordenada por Pedro Espinosa, Valladolid, $160_{5}$, fol. $47 \mathrm{r}^{\mathrm{a}}-\mathrm{v}^{\mathrm{o}}$. Cf. la ed. de J. Quirós de los Ríos y F. Rodríguez Marín, Sevilla, 1896, p. 87 (y la nota respectiva, p. 362). Acerca del autor, véase el voluminoso libro de Joaquín Hazañas y La Rúa, Vázquez de Leca (1573-1649), Sevilla, 1918. El soneto está también en el ms. 4117 de la B. N. M., fol. $74 \mathrm{v}^{\circ}$, con este epígrafe: "Trisca", que no entiendo (en folios anteriores hay sonetos con epígrafes más claros: "Lope", "Servantes"). Fue traducido al inglés por Sir John Bowring, quien, naturalmente, no pudo encontrar un juego de palabras equivalente, y prefirió dar al soneto otro remate, de su propia cosecha: "...True, love may graze us, -but the drowning plan / is a mistake, which neither oil nor ointments, / nor wit, nor wisdom, can get over, man" (The sonnets of Europe, A volume of translations, sel. and arranged, with notes, by Samuel Waddington, London, 1886 [y también: New York, 1887], p. 181). 
Muy aficionados a nuestro chiste se muestran en el primer cuarto del siglo xvn dos grandes poetas conceptistas: Alonso de Ledesma ${ }^{10}$ y sobre todo don Francisco de Quevedo. El primero de ellos nos propone en sus Juegos de Nochebuena la siguiente adivinanza -cuya respuesta, naturalmente, es "El Huevo":

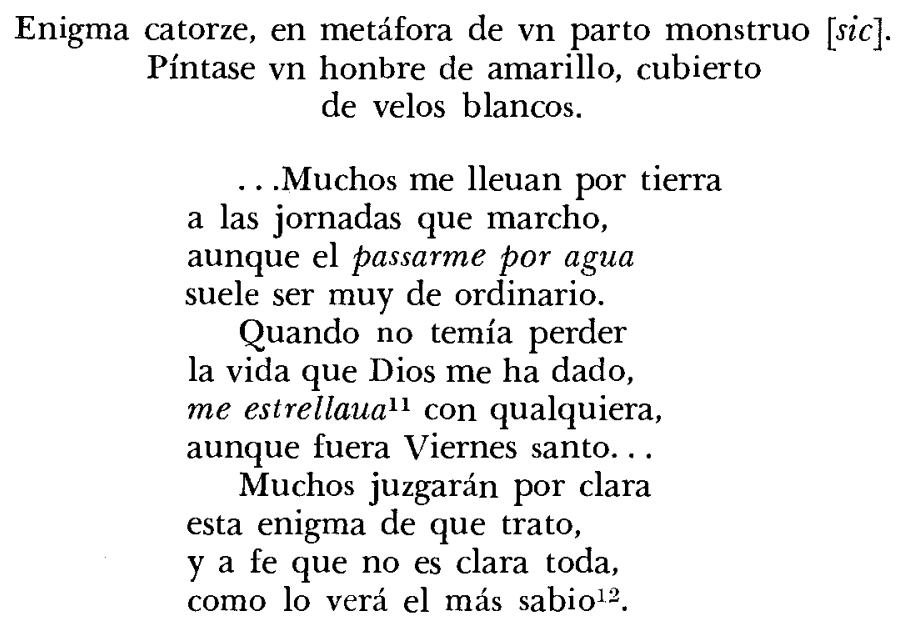

$\mathrm{Y}$ en sus Epigramas y hieroglificos repite parcialmente la agudeza, aplicándola nada menos que a la Virgen María. Hay en ese librito (fols. $67 \mathrm{v}^{\circ}-84 \mathrm{r}^{\circ}$ ) un largo "Coloquio entre la Fama y Erezma, río de Segouia", acerca de las grandezas y antigüedades de la ciudad. El río presenta en una cuarteta cada una de las cosas notables: "Ésta es la famosa puente...", "Éste es el Alcázar real. ..", etc., y la Fama dedica a cada una de ellas una décima de ingenioso comentario. Una de las "grandezas" es la imagen de la Virgen de los Huertos, traída milagrosamente por las aguas del propio río Eresma durante una peste que afligía a Segovia:

10 Es raro que no se mencione a Ledesma en la historia de la literatura de Ángel Valbuena Prat (ed. de 1946) ni en la de Ángel del Río (ed. de 1948). Lo estudian, en cambio, ángel González palencia y Juan Hurtado, ed. de 1949, p. 522, y sobre todo Ludwig Pfandl, Historia de la literatura nacional española de la Edad de Oro, trad. J. Rubió Balaguer, Barcelona, 1933, pp. 5175I9. Recientemente, el profesor Florian L. SMIEJA ha escrito sobre él una amplia y erudita tesis, aún inédita: The poetry of Alonso de Ledesma, with special reference to the rise of the religious "concepto". (Al profesor Smieja debo el conocimiento del segundo de los textos de Ledesma que aquí reproduzco, como también el de la Gatomaquia de Lope, que luego copiaré).

11 "Estrellarse una persona con otra -explica Covarrubias (Tesoro, s. v.)- es arrojarse a dezirle su parecer libremente, y oponérsele con peligro de perderse, siendo más poderoso el acometido".

12 Alonso de Ledesma, Juegos de Noche Buena moralizados a la vida de Christo, martirio de santos y reformación de costumbres, Madrid, 1611, fol. ${ }_{164} \mathrm{r}^{\circ}-\mathrm{v}^{\circ}$. 


\section{Erezma:}

Esta Virgen de los Huertos vino por el río Erezma, como droga en infusión, estando Segouia enferma.

\section{FAMA:}

Traxo Erezma en agua vn día vna imagen de marfil, que por lo blanco y sutil forma de hueuo tenía: Es del Aue de María, y según Segouia está, cena de enfermo será, tan sana como suaue; porque el hueuo de tal Aue passado por agua $\mathrm{va}^{13}$.

Y he aquí, ahora, a don Francisco de Quevedo. Sea primero el romance intitulado "Suceso nocturno", en el cual nos describe su encuentro con dos horrorosas estantiguas, mujeres de mala vida:

Salió trocada en menudos

la luna en su negro coche, y diome su luz en quartos que parecieron chanflones.

Estrellada como huebo salió la mulata noche; estaua Pisuerga mudo, Eco roncando en sus montes. . ${ }^{14}$

Muy parecido a éste es otro romance en que el poeta relata su abyec-

13 Alonso de Ledesma, Epigramas y hieroglificos a la vida de Christo, festiuidades de Nuestra Señora, excelencias de santos y grandezas de Segouia, Madrid, 1625 [edición póstuma], fol. $74 \mathrm{v}^{\circ}$. (Es libro bastante raro; sólo he visto un ejemplar en la H. S. A. y otro en el British Museum; este último lleva, por cierto, el sello de la Biblioteca Nacional de Lima). -Parecido juego de palabras y parecidas rimas había empleado Hernán Gonzalez de Eslava en su Coloquio XIV, "De la pestilencia que dio sobre los naturales de México", en el cual, con su ingenua técnica de costumbre, extrae una enseñanza espiritual de la calamitosa peste de 1576 . (El coloquio puede haberse escrito el año siguiente). Al final se alegoriza la convalecencia del Enfermo; pregunta la Clemencia: "¿Y podrá comer de un ave?”; y contesta el Remedio: "Coma un ave cada día, / digo, de un Ave Maria, / que es comida muy suave / de consuelo y alegría" (Coloquios espirituales y sacramentales [1610], ed. J. García Icazbalceta, México, 1877 , p. 185).

${ }^{14}$ Cito por el ms. 3890 de la B. N. M., fols. $17 \mathrm{v}^{0}$-19 $\mathrm{v}^{0}$, que habrá que añadir a los tres que menciona L. Astrana Marín en su ed. de las Obras en verso de Quevedo, Madrid, 1943, p. 242. (La versión de ese ms. parece coincidir con la del que copió Gallardo, que es el tercero de los que menciona Astrana). 
ta aventura con una monstruosa prostituta, "frisona en lo gordo, / punto menos que elefante". El romance comienza también con una descripción de la noche:

\author{
...La luna, entre clara y yema, \\ alumbraba a los mortales \\ (que mi gana de comer \\ buscó apodo semejante)... \\ Viendo estrellada la noche, \\ la noche quise cenarme. . ${ }^{15}$
}

Una de las más escalofriantes caricaturas del amor y de la mujer que llegó a escribir Quevedo es su romancillo "Hero y Leandro en paños menores"16, furioso vendaval que destruye, implacable, hasta la menor brizna de idealismo y ternura en la historia de los legendarios amantes. A él, Quevedo, no le interesan "pataratas", sino la "verdad", la verdad desnuda, sórdida, feroz. El epitafio burlesco de Góngora es aprovechado y minuciosamente glosado. Primero, en la parte relativa a Leandro, ese "aprendiz de rana". ¿Se va a ahogar en las olas del Helesponto? Muy bien, nada más natural:

\author{
Ya no hará en sorberse \\ el mar mucha hazaña \\ un amante huevo \\ pasado por agua...
}

Y luego, muy particularmente, en la parte relativa a Hero, "moza de una venta..., / corita en cogote / y gallega en ancas". Góngora se limitaba a decir que la doncella de Sesto murió "estrellada" como huevo. Quevedo necesita aclarar, acentuar, recargar. Para freír un huevo hace falta aceite; y aquí hay aceite a la mano: el de la lámpara que Hero enciende en la torre, o mejor dicho, el candil que ella asoma "por una ventana, / farol de cocina / que el viento le apaga". La Hero-Maritornes de este romancillo, después de su último discurso,

calló, y lo primero

el candil dispara,

y, por no mancharse,

las olas se apartan.

Se apartan las olas, muertas de asco, y dejan que el candil escacha-

15 Obras en verso, ed. cit., p. 253. Con varıantes -que no afectan al pasaje que aquí copio-, en las Poesias varias... recogidas por Josef Alfay (ed. J. M. B[lecua], Zaragoza, 1946, pp. 37-40), versión reproducida por Astrana Marín en un "Post scriptum" de su edición, pp. $1535^{-1536 .}$

16 Véase mi art. cit., "Los romances de Hero y Leandro", pp. 29-32. 
rrado derrame el aceite sobre la piedra viva. Se arroja entonces Hero desde la torre:

dio sobre el aceite

del candil, de patas;

y en aceite puro

se quedó estrellada.

En el epitafio -escrito por Amor "con letra bastarda" - resuena no sólo el eco de Góngora, sino también el del soneto de Vázquez de Leca ("y cenóse el diablo el par de hueuos"):

\author{
“Cual güevos murieron \\ tonto y mentecata; \\ Satanás los cene, \\ buen provecho le haga"17.
}

Por último ${ }^{18}$, en el exuberante "Baile de los nadadores", Quevedo da un paso más. Hero y Leandro, prototipos de los amantes, son un par de huevos (verdad establecida): huevos serán también todos sus seguidores, los mil y mil mentecatos de toda laya que van tras sus huellas. No sólo estrellados y pasados por agua, sino fritos y revueltos, tiernos y asados, dulces y en tortilla, perdidos y hueros....

Los amores, madre, son como huevos:

los passados por agua son los más tiernos.

Leandro en tortilla, estrellada Ero;

los pobres, perdidos; los ricos, rebueltos;

los zelosos, fritos; asados los necios;

los pagados, dulces; los sin blanca, güeros ${ }^{19}$.

17 Obras en verso, ed. cit., pp. 243-245 (versión del Parnaso español de González de Salas), y Apéndice XII, pp. $1267-1269$ (versión del ms. 3797 de la B. N. M., que ofrece muchísimas variantes).

18 No me consta, por supuesto, cuál sea el orden cronológico de las composiciones de Quevedo que aquí estudio. Las fechas que da L. Astrana Marín parecen casi siempre caprichosas y sin fundamento, y creo que será mejor no tomarlas en cuenta. El problema de la cronología quevedesca es ciertamente peliagudo. Todos esperamos que la próxima edición de José Manuel Blecua arroje mucha luz sobre él.

19 Romances varios de diuersos autores, agora nueuamente recogidos por el licenciado Antonio Diez, Zaragoza, 1663, pp. 109-114 (y también Obras en

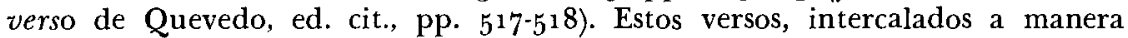
de estribillo, se repiten al final del "Baile", con una variante en el último: "los sin paga güeros". 
Después de estos pasajes de Quevedo, sobre todo el romancillo de Hero y Leandro, cargado de pasión, preñado de saña y de ponzoña, las ingeniosidades de Salas Barbadillo nos suenan necesariamente a cosa hueca. Nuestro chiste reaparece en la "Auentura segunda" de Don Diego de Noche, en un "Epistolario yocoso" que es más bien un arduo ejercicio retórico. Salas Barbadillo, escritor perfectamente representativo de la vaciedad intelectual de la España post-tridentina, no nos trae nada a nosotros, como no sea el testimonio de esa atmósfera de frío sepulcral. La Epístola undécima, dirigida "A vn corredor de mohatras, auiéndosele anegado vn hermano en la mar", abunda en simétricas y cerebrales antítesis:

...Su hermano de V.m. al tercer día de su nauegación se ahogó en la mar: y V.m., tras tantos años, nunca ha corrido tormenta en las ondas de la Puerta de Guadalaxara. Auenturóse el moçuelo a la jornada de las Indias con peligro del mar inconstante: V.m., con seguridades infalibles, halla las Indias en breue orizonte. Mas es la distinción del caso, que el difunto passado por agua se yría a ser estrellado en el cielo: y V.m., fatigando la tierra, está muy cerca de rodar al infierno...20

En cambio, Quiñones de Benavente no carece de gracia y de humor. Un humor muy distinto del de Quevedo, no sarcástico y venenoso, sino discreto y urbano. En la Jácara que se cantó en la compañia de Olmedo hay una cómica riña de Osorio con tres de las actrices:

$$
\begin{aligned}
& \text { Osorio-Estas jembras no se acuerdan } \\
& \text { que en los almendros de Olías } \\
& \text { yo fui Conde de Carrión, } \\
& \text { y ellas del Cid fueron hijas. } \\
& \text { Pues por el agua mehor, }
\end{aligned}
$$

20 Alonso Gerónimo de Salas Barbadillo, Don Diego de Noche, Madrid, 1623, fols. $39 \mathrm{r}^{\circ}-40 \mathrm{r}^{\circ}$. MYron A. Peyton, "Salas Barbadillo's Don Diego de Noche", PMLA, 64 (1949), 484-506, observa que el ingenio de este autor "tends to be either callous, coarse, or in bad taste, judged by our standards of today", y cita como ejemplo de esta tosquedad y dureza la frase "el difunto passado por agua", aplicada al pobre mozuelo que se ha ahogado en el mar (loc. cit., pp. 501-502). De hecho, Quevedo puede ser infinitamente más duro y grosero, y sin embargo su humor no nos deja insensibles. Lo malo de Salas Barbadillo no es, creo yo, su "callousness", sino esa cualidad deshumanizada de su obra, en la que pocas veces encontramos algo que se parezca a la vida. Hay que añadir que el artículo de Peyton es muy valioso, lo cual me temo que no se pueda decir del de Raymond L. Grismer, "Classical allusions in the poetic works of Góngora", $H, 30$ (1947), 496-504. Grismer, incapaz de comprender el arte de Góngora, lo condena con gran severidad porque "our poet does not approach that inexhaustible spring of poetic inspiration, mythology, with the respect and seriousness that many of us feel are due it" (y pone, entre otros ejemplos, el romance "Arrojóse el mancebito", tan irrespetuoso y "ofensivo"). 
que es la del avemaria, que si... -quédese en que si; no descubramos la tiña. Antonia-¡Tiñosas nos ha llamado! ¡Ay, qué deshonra enfermiza! ¡ay, qué agravio de hospital! ¡ay, qué asquerosa mohína! Pues, espulgón madrigado, delincuente sarnicida, ¿cómo la opinión abollas de un tres en raya de ninfas?

VICENTA-;Alto, yo quiero estrellarle!

JACINTA- ¡Yo quiero hacerle en tortilla!

Antonia-Y yo pasarle por agua, que es la muerte más mezquina ${ }^{21}$.

Tras Quiñones de Benavente sigue en este desfile un personaje inesperado: el humanista valenciano Vicente Mariner, traductor fenomenal que puso en latín un número increíble de versos griegos y de anotaciones de los escoliastas, y autor asimismo de decenas de miles de versos latinos originales, casi siempre "panegíricos" y piezas de circunstancias. Seguramente data de 1623 , el año en que estuvo en España el Príncipe de Gales, Carlos Estuardo, la extensa composición latina a él dedicada: Panegyris ad serenissimum Carolum Stubardum, Wallia Principem, Magnce Britannia heredem, en la cual interpola, sin venir muy al caso, hasta 324 hexámetros que narran los amores de Hero y Leandro:

Littore divisus, sed multo junctus amore magnus Abydenus dum nat freta pervia ponti, Sestana ardebat vehementiùs igne puella...

Los versos de Mariner, preciso es confesarlo, no son ninguna maravilla. Escritos evidentemente muy de prisa, carecen de elegancia y pulimento, y prodigan los vulgarismos de vocabulario y de sintaxis en mucho mayor medida que los de los humanistas del siglo xvi. Desde luego, no se puede comparar a este coetáneo de Lope de Vega con un Juan Verzosa o con un Arias Montano. En todo caso, su relato de la historia de Hero y Leandro va perfectamente en serio, con algún leve sabor ovidiano, hasta que de pronto, de manera abrupta y absurda, cambia el tono. La tentación de terminar con el chiste de Góngora ha sido irresistible. Hero decide arrojarse desde la torre al ver el cuerpo muerto de Leandro:

21 E. Cotarelo y Mori (ed.), Colección de entremeses, loas, bailes, jácaras y mojigangas..., t. 1, vol. 2 ( $N B A E, 18$ ), Madrid, 1911, p. $5^{1} 5^{a}$. Debo la noticia de este texto a Hannah E. Bergman, la máxima conocedora de la obra de Quiñones. 
Tunc cecidit, fregítque artus, vitámque reliquit, perfractisque suis siluit morte incita membris, utque oyum periere ambo sub cortice toto: hic sub aquis mersus, detritis artubus illa ${ }^{22}$.

(Claro que el chiste no tiene ya, en latín, ni sombra de sentido).

En la Silva segunda de la Gatomaquia, una de sus últimas obras -publicada en ${ }_{16} 6_{34}$, introduce Lope de Vega una breve parodia de los versos de Góngora, "Era del año la estación florida..." Se trata, como en el comienzo de las Soledades, de una complicada alusión perifrástica a la época del año, con mención mitológica de una de las constelaciones del Zodíaco: el signo de Géminis, compuesto de dos estrellas, en las cuales convirtió Júpiter a sus hijos Cástor y Pólux (nacidos del "huevo azul de Leda"):

Estaba el sol ardiente una siesta de mayo calurosa, aunque amorosamente, plegando el nácar de la fresca rosa, que producen los Niños abrazados, huevos del Cisne (y huevos estrellados, pues que los hizo estrellas), cuando Mizilda con las manos bellas la cara se lavaba y componía... ${ }^{23}$

Superficial es el recuerdo del chiste en el gracioso Panegirico al chocolate $\left({ }_{1640}\right)$ del capitán Castro de Torres:

Cuando vienen del Sur los galeones y tormenta deshecha los combate; cuando los amenazan los tritones y como a güevos los revuelve y bate, ricos al mar arrojan los cajones de plata y oro: sólo al chocolate de conservarle todo el mundo trata: iperezca el oro, húndase la plata! ${ }^{24}$

El ingeniosísimo Jerónimo Cáncer da un nuevo y sorprendente giro al chiste de los huevos en una breve vida de Santo Domingo de Guzmán, escrita en quintillas, cada una de las cuales contiene una

22 Vincentii Marinerii Valentini Opera omnia, poetica et oratoria in IX. libros diuisa.... Turnoni, 1632 (imponente volumen de 863 apretadas páginas). La Panegyris al Principe de Gales está en las pp. 216-276; el pasaje sobre Hero y Leandro, en las pp. 242-252. Véase la comunicación de J. Serrano Caldero, "Las obras del humanista Vicente Mariner $\left(\nmid 164^{2}\right)$. Sus manuscritos existentes en la Biblioteca Nacional de Madrid", en Actas del primer Congreso español de estudios clásicos, Madrid, 1958, pp. 500-506.

${ }^{23}$ La Gatomaquia, ed. F. Rodriguez Marin, Madrid, 1935, pp. 25-26.

${ }^{24}$ Cit. por Gallardo, Ensayo, t. 2, col. $35^{6}$. 
agudeza piadosamente irreverente. Dicen las vidas del santo que en el momento de bautizarlo apareció una estrella luminosa en su frente. Ya tiene Cáncer los elementos para reelaborar el chiste de Góngora y dejarlo como nuevo:

Diéronle con gran cuidado

el bautismo consagrado, donde la gracia se fragua;

y al ille a passar por agua

vieron que estaua estrellado...25

Cáncer, el más brillante de los continuadores de Ledesma, ejerció a su vez muy gran influencia sobre los poetas de convento y "villanciqueros" a lo divino durante la segunda mitad del siglo xvn y aun en el xvirr. Uno de sus seguidores ${ }^{26}$ es el aragonés Vicente Sánchez, coplero "oficial" a quien se acudía cada vez que se celebraba en Zaragoza la solemne profesión de una monja, y a quien se encargaban, año tras año, los villancicos que se cantaban en las más sonadas fiestas de la iglesia. Vicente Sánchez repite casi a la letra el chiste de Cáncer en una jácara "A Santo Domingo" (que empieza "Oyga, reuerendo padre..."):

..Tuvo estrella al bautizarse, milagro que me suspende, que al ser passado por agua estrellado pareciesse ${ }^{27}$.

La Lyra de Sánchez nos ofrece otras tres composiciones dedicadas al mismo santo. En las tres se alude a la estrella, pero el poeta, consciente de que los devotos que escuchan su villancico en la iglesia son los mismos que han oído y festejado el del año anterior, hace lo indecible por no repetirse. He aquí una de esas alusiones:

$$
\begin{aligned}
& \text {...mas por cierto tengo yo } \\
& \text { que si el santo se estrelló, } \\
& \text { con los hereges sería }{ }^{2 s},
\end{aligned}
$$

donde ya no se piensa, claro está, en el huevo estrellado.

Éste vuelve a aparecer, en cambio, en otra reelaboración que hizo Cáncer del viejo chiste. Si en el bautismo de Santo Domingo había

25 Gerónimo Cáncer y Velasco, Obras varias, Madrid, 1651, fol. $53 \mathrm{r}^{*}$. Las quintillas se pueden leer también en las Delicias de la lengua castellana, Milán, $16_{55}$, p. 88 (var.: “y allí al passarlo por agua..."). Véase F. LÁzAro Carreter, art. cit., p. 368 .

${ }_{26}$ No cuento entre ellos a don Pedro de Vargas Maldonado, de quien he visto unas Poesías. .., 1679, copia manuscrita del siglo xix (H. S. A.); la composición sobre Santo Domingo que allí aparece es simplemente la de Cáncer.

27 Vicente Sánchez, Lyra poética, Zaragoça, 1688 [ed. póstuma], p. 111.

28 Ibid., p. 112. Sobre estrellarse en este sentido, cf. supra, nota 11. 
agua, en el martirio de San Juan Evangelista había aceite hirviendo. Era preciso sacarle partido. Y así lo hace Cáncer en su divertida jácara "A S. Iuan Euangelista en el martirio de la tina":

...Adoleció de vna Tina, que es vn(a) achaque mui malo, y estuuo tan de peligro, que llegó [a] estar oleado.

Salió burlando el martirio, más terso, luciente y claro, que el azeyte le ayudó a parecer estrellado.

Con todo, desde aquel día no quedó mui limpio el santo, que las lámparas le duran hasta en sus mismos retablos ${ }^{29}$.

Las posibilidades del chiste no dejaron de ser explotadas en Portugal. He encontrado variantes en tres poetas de esta nación: Jacinto Freire de Andrade (1597-1657), António Serrão de Castro (16101684?) y Jerónimo Baia $(\dagger 1688)$.

Freire de Andrade recurre a la imagen del huevo en una Fabula de Polifemo e Galatea escrita en "romance burlesco", que se inicia con una alusión expresa al Polifemo de Góngora:

Lá donde o mar de Sicilia, diz o Cordovez famoso, lava os joannetes daquelle levantado promontorio...

El poeta portugués altera el desenlace de la fábula. Según él, Acis y Galatea "estavão juntos hum dia, / ella pomba e elle pombo", cuando los vio el cíclope, el cual tomó sin más ceremonias al mancebo y lo partió en dos contra una peña, como quien parte un huevo para freírlo:

...e pegando do coitado, como quem pega de hum ovo, deu com elle n'hum penhasco e fez-lhe em cacos o corpo ${ }^{30}$.

Jerónimo Baia inserta íntegramente el chiste en otro romance mitológico burlesco, la Fabula de Jupiter e Europa, llena de los equívocos habituales en esta clase de obras a lo largo del siglo xvn.

29 Obras varias, fols. $73 \mathrm{r}^{\circ}-74 \mathrm{r}^{\circ}$; Delicias..., pp. $\log ^{-111}$. También esta jácara figura, íntegra, entre las Poesias de VARGas Maldonado, ms. cit.

30 Cito por la $2^{a}$ ed. de $A$ Fenix renascida, t. 3 , Lisboa, 1746 , pp. 322-328. 
Júpiter, que bajo la figura de un toro ha sido "el mentido robador de Europa", abandona el disfraz una vez consumada su fechoría:

...Mudou Jupiter a pelle,

porém foy só na apparencia;

pois bem que a pelle mudou,

na vida não poz emenda.

Poz Jove o touro no Ceo,

e porque foy nesta empreza

no mar passado por agua,

ficou estrellado na esfera ${ }^{31}$.

"Estrellado", porque es ahora una de las constelaciones del Zodíaco. (Recordemos a Cástor y Pólux en la Gatomaquia, "estrellados" también, aunque no pasados por agua).

António Serrão de Castro (o "de Crasto"), autor del notable poema satírico Os ratos da Inquisição, fue miembro de la Academia dos Singulares de Lisboa $\left(166^{-1665}\right.$ ), donde se leyeron infinidad de versos aburridísimos que el estudioso puede ver en dos polvorientos volúmenes impresos en 1665 y 1668 . El "assumpto" de la décima academia o sesión fue "o naufragio [sic] de Leandro, \& despenho de Hero", y sobre él se hicieron cuatro sonetos españoles y dos portugueses, y una silva y un romance en portugués. Serrão de Castro leyó un soneto con cola ("Hoje he Leandro bacalhao de molho..."; las rimas son -olho, -alho, -ulho, -ilho). He aquí el último terceto y la cola. Muertos ya Hero y Leandro,

Ambos juntãrão, quaes dous grãos de milho, delles fizerão de hũa cova entulho, e estas letras lhe abrem cum pampilho:

"Dous ovos aqui com magoa

Amor tem depositado:

hum em fatias quebrado, outro passado por agoa"32.

También fuera de España, pero esta vez en los Países Bajos, nos encontramos con la contradictoria figura de Miguel de Barrios, o, con su nombre de converso al judaismo (verdadero nouveau juif), Daniel Leví de Barrios. La poesía en que inserta el chiste de los huevos forma parte de una larga y apasionante historia, excelentemente estudiada hace poco por I. S. Révah ${ }^{33}$. En 1656 , el supremo Mahamad de Amsterdam excomulgó a dos heterodoxos, uno poco

31 Publicada ibid., pp. 158-169.

32 Academia dos Singulares, Tomo segundo, Lisboa, 1668, p. 255. (Reimpreso a plana y renglón en la misma ciudad, 1698). ¿Por qué em fatias quebrado y no simplemente estrelado? ¿No sería muy común en portugués el verbo estrelar en ese sentido? Pero cf. supra los versos de Baia.

${ }^{33}$ I. S. Révah, Spinoza et Juan de Prado, Paris-La Haye, 1959. 
conocido, llamado Juan (o Daniel) de Prado, y el otro famosísimo: Baruch Spinoza. Nueve años después, Juan de Prado se encuentra en la parte católica de los Países Bajos, y dedica a Miguel de Barrios un soneto que se publica en los preliminares de un libro de éste, la Flor de Apolo (Bruselas, 1665). A Barrios, judío nada ortodoxo, no le molestaba evidentemente la situación de Prado, expulsado de la comunidad de Amsterdam por sus ideas "ateístas" (o mejor, deístas) y por sus tendencias epicúreas. Pero unos años después muere Prado en un accidente. Y esta vez, Barrios no tiene empacho en lanzar una feroz invectiva contra el amigo de otros días, quizá para congraciarse con las comunidades judías ortodoxas. La poesía va precedida de un largo epígrafe en que se explican las circunstancias de la muerte de Prado y se recuerdan sus ideas ateístas y materialistas:

Castiga la Divina Justicia al Doctor Juan de Prado, maestro de falsos dogmas ${ }^{34}$, que no tenía más religión que la que convenía a su cuerpo, ni más alma en su opinión que de cavallo; y dando palabra de casamiento a una Fulana Loba, la desfloró; y yéndose a casar con otra, ordenó la Suprema Justicia que, por un carro que se le atravessó en una puente, cayesse della con su cavallo en un río, donde le imitó en la muerte como en la vida ${ }^{35}$.

La poesía, en quintillas, está llena de los juegos conceptuales de moda. Barrios se esfuerza en terminar cada quintilla con una agudeza: ". . Don Quixote en Rozinante, / y en el comer Sancho Pança"; "...donde, como era gran perro, / osó embestir a una Loba", etc. Hacia el final, recuerda expresamente la historia de Hero y Leandro:

Por la Ero que amó astuto,

Leandro de la ficción, nadava de llanto enjuto; tan César de su opinión, que a morir vino por Bruto.

Pero antes, hay otras dos quintillas que dicen:

Su estrella quedó tan rota, que, por el divino fallo, quando de hombre dio más nota, queriendo triumphar de sota se vio arrastrar de cavallo.

Imitó al hijo de Phebo,

34 "Il est... clair que, pour les contemporains Sefardim d'Amsterdam, naturellement mieux renseignés que les biographes tardifs de Baruch, c'était le Dr. Juan de Prado qui était le véritable responsable de l'apostasie du jeune Spinoza" (RÉVAH, op. cit., p. 23).

35 Es curioso encontrar aquí los mismos elementos que en la anécdota de la Miscelánea de Zapata (supra, nota 5): el jinete, el caballo, el puente, el rio (y, luego, la expresión "pasado por agua"). No se sabe la fecha exacta de la muerte de Juan de Prado (cf. RévaH, op. cit., p. 35). 
que a cavallo subió osado:

pues por el carro, estrellado

cayó, donde como huebo

se vio por agua passado ${ }^{36}$.

En la poesía de Barrios acabamos de ver una alusión a Don Quijote. La aventura de los Batanes de Don Quixote de la Mancha es el asunto que eligió el licenciado Francisco Paços para un romance de pie quebrado, leído en ${ }^{16} 65$ en una academia madrileña. El romance comienza, como los dos de Quevedo, con una descripción de la oscuridad de la noche:

...La noche huyó de ser huevo:

que además de no ser clara,

no tuvo vna luz mexida

ni estrellada ${ }^{37}$.

Años después, en 1684 , se cantaban en México unos villancicos de Sor Juana Inés de la Cruz en honor de San Pedro Apóstol ${ }^{38}$. El sexto villancico se refiere al episodio de Simón Mago, narrado en los Hechos de los Apóstoles, y termina así:

A otro $\operatorname{Simón}^{39}$ pagarás tu grosero atrevimiento, que le ayunan las vigilias los más briosos al Viejo ${ }^{40}$.

A fe que presto lo vio: volar quiso el hechicero, y sin decir "Dios me valga", estrellóse como un huevo.

(Pocos años antes, en un villancico en honor de la Limpia Concepción, Sor Juana había dicho que la Virgen "la cabeza se estrelló / sin haber dado caida") ${ }^{41}$.

36 Miguel de Barrios, Coro de las Musas, Bruselas, 1672, pp. 355-361. Poesía reproducida por RÉVAH, op. cit., pp. 7o-74.

${ }_{37}$ Academia que se celebró por Carnestolendas..., Madrid [1675], pp. 7678. Cf. otra poesía de academia, la Fábula de Iúpiter y Semele, Iocoseria, de don Juan de Salcedo Ponce de León, escrita en "endechas endecasýlabas" (Academia que se celebró en Badajoz..., Madrid, 1684 , fols. $22 \mathrm{v}^{0}-24 \mathrm{r}^{\circ}$ ): después de dejar achicharrada y hecha ceniza a la pobre Semele, Júpiter "empeçó muy de espacio / a escarbar la ceniça con su cetro. // Y en ella vn tierno infante, / que él mismo le auía hecho, / estaua: ¿y quál estaua? / en la forma que suele assarse on hueuo".

38 Sor Juana Inés de la Cruz, Obras completas, ed. Alfonso Méndez Planearte, t. 2, México, 1952, p. 299.

${ }^{39}$ Sor Juana se dirige aquí al Mago; el "otro Simón" es Simón Pedro.

40 Méndez Planearte explica (loc. cit., p. 497): 'hasta los más valientes tienen respeto y rinden culto a San Pedro'.

41 Obras completas, t. 2, p. 20. 
Ya muy entrado el siglo xviri, Manuel Montañés y Monte-Alegre escribe un largo "Obillejo" en el cual "Refiere las desgracias que padeció desde Salamanca a unas Aldeas llamadas las Taberas", relato que quiere ser humorístico:

...Quando assí piso sombras, dudas sigo;

el Cielo todo se estrelló conmigo;

pero ¿qué lo dudaba mi desvelo,

si ya dexé estrellado a todo el Cielo?...

"Viendo quán poco alumbran las estrellas", el poeta les dice, "por conjuro", un estrafalario soneto: "Signos de mi desdiha [sic], astros errantes. .", cuyos tercetos contienen un apóstrofe en el cual se aplica nuestro chiste, como en la Gatomaquia de Lope, a la constelación de los Gemelos:

Y vos, hijos de un huevo, ya estrellado, Cástor y Pólux, dos alhajas raras, pues un Poeta veis descalabrado, decid, hijos de puta, y a las claras: ¿por qué la cataplasma avéis negado, teniendo en vuestras luces tantas claras? ${ }^{42}$

Lo más notable del chiste cuya historia se acaba de leer me parece, no tanto su perduración a través de un siglo y medio, cuanto la variedad de facetas y sentidos que a lo largo de ese tiempo llegó a desarrollar ${ }^{43}$. No lo he encontrado con posterioridad a 1735. Recojo, sin embargo, dos ejemplos modernos de la expresión pasado por agua, empleada para designar al hombre que, física o espiritualmente, ha cruzado el Atlántico. En 1868, Manuel del Palacio publica en Madrid su libro Un liberal pasado por agua: Recuerdos de un viaje a Puerto Rico. Y hacia ${ }_{1} 886$, doña Soledad Olaguíbel de Maillefert expresaba su aprecio por Manuel Gutiérrez Nájera, su futuro yerno, como "hombre. . pasado por agua", es decir, 'culto', conocedor de la literatura y el arte europeos ${ }^{44}$.

42 Poesias lyricas, que escrivia don Manuel Montañés y Monte-Alegre, dedicadas a la gloriosa virgen y mártyr Santa Bárbara..., Madrid, 1735, pp. 155168 (el soneto, en las pp. 163-164).

$43 \mathrm{H}$. N. Bershas termina asi su estudio sobre el chiste de los cardenales (art. cit., p. 26): "The foregoing list amply attests the vigor of the pun as well as its Protean mutations. Truly, in the hierarchy of nobility of word plays, this one must be accounted a Prince of Wales". A mí, francamente, no me parece muy "proteico" ese juego de palabras; los términos son siempre los mismos: cardenal 'moretón' (de ordinario, el que dejan los azotes) y cardenal 'príncipe de la Iglesia', mientras que en el chiste de los huevos, los sentidos figurados de estrellado y de pasado por agua son muy variados.

44 Margarita GutiÉrez NÁJERA, Reflejo: Biografía anecdótica de Manuel Gutiérrez Nájera, México, 1960, p. 66. (Debo este dato a Raimundo Lida). 


\section{APÉNDICE}

La afición de los poetas barrocos a entretejer de chistes sus composiciones en honor de Cristo, la Virgen y los santos, puede parecer chocante a los lectores de hoy, sobre todo si son espíritus religiosos. Nos hallamos ante un fenómeno histórico-social que solicita nuestra comprensión, y que bien merecería la atención cuidadosa de los hispanistas. Es claro que esos poetas no se sentían culpables de irreverencia cuando decían que Cristo, azotado y sangrante desde la coronilla hasta la planta de los pies, "llamó a congregación de cardenales", o cuando declaraban, a propósito de la negación de San Pedro, que no era maravilla que el gallo cantara al ver semejante gallina, o que el mismo San Pedro, al cortarle a Malco la oreja, habia argumentado con un silogismo en ferio, o que Santo Domingo, al mortificarse con azotes, "un domingo quebrantaba / muy sin cargo de conciencia".

En las páginas que preceden hemos visto varios de estos chistes en jácaras y villancicos dedicados a la Virgen María (Ledesma, Sor Juana Inés de la Cruz), a Santo Domingo de Guzmán (Cáncer, Vicente Sánchez), a San Juan Evangelista (Cáncer) y a San Pedro Apóstol (Sor Juana). Para redondear un poco la materia, voy a ocuparme aquí de otras composiciones poéticas relacionadas en alguna forma remota con el chiste de los huevos, o que muestran un tipo análogo de "humor culinario".

El punto de partida es Alonso de Ledesma. "Hoy es inimaginable -dice Fernando Lázaro Carreter ${ }^{45}$ - la fama de este escritor a quien sus contemporáneos dieron el dictado de divino. Ledesma concibe siempre de manera alegórica. Asombra su capacidad para descubrir insospechados paralelos entre las cosas". Lázaro menciona a varios de sus secuaces, como Alonso de Bonilla, Jerónimo Cáncer y el predicador Jerónimo de Florencia, grandes adeptos de la alegoría conceptista y del juego de palabras. En este Apéndice nos encontraremos con otros nombres, menos conocidos, de poetas que cultivan el chiste piadosamente irreverente.

Hemos visto antes la jácara donde Cáncer dice que San Juan Evangelista, en la tina de aceite hirviendo, parecía huevo estrellado. Ledesma hizo sobre ese asunto varias composiciones festivas. Una se intitula "A S. loan Evangelista ante portam Latinam ${ }^{46}$, en metáfora de freýr peces". Lleva al margen algunas glosas explicativas, para la mejor comprensión de los equívocos:

\section{Concepto}

A pescar se puso Dios en el mar de Galilea, y quantos peces dessea los saca de dos en dos. Vno grande fuystes vos,

(Apóstoles)

(Excelencias del Euangelista) y dixo Pedro está vez: "¿Qué se ha de hazer deste pez, que me parece el mayor?"

45 "Sobre la dificultad conceptista", art. cit., p. $3^{62}$.

4o Así se llama, en efecto, la festividad litúrgica del martirio de este santo (martirio en que no murió): In festo $S$. Ioannis ante Portam Latinam (6 de mayo). 
Respondióle el pescador:

"Quiérole para guardar,

(Sic volo eum manere)

y pues tanto ha de durar,

frito quedará mejor" 47.

(Martyrio)

Otra de las poesías desarrolla una metáfora diversa, pero siempre a base del aceite:

Sois lámpara, luan sagrado, de gran luz y resplandor,

y aora luzís mejor

del modo que os an ceuado. . ${ }^{48}$

Y en otra más, una tercera metáfora cuyo punto de partida no es ya el "aceite", sino la "tina":

Vn tintorero traydor oy ha metido en su tina vn paño de lana fina para mudalle el color. . . ${ }^{49}$

En el epigrama a Santo Domingo de Guzmán, Ledesma no dice nada que anuncie la genial innovación de Cáncer. Pero en la página dedicada a San Nicolás Tolentino, a quien se representa con un hábito sembrado de estrellas, encontramos este jeroglífico: "Pintóse vn cielo todo estrellado", y esta letra:

Si al cielo de vna alma justa

falta nube de pecado, ¿qué mucho se vea estrellado? 50

Un seguidor de Ledesma, Juan de Luque, "natural de Jaén", publica en 1608 tres villancicos "A S. Iuan Evangelista en la Tina", pero sus metáforas siguen otro camino. He aquí un breve ejemplo, gracioso por

${ }^{47}$ Alonso de Ledesma, Tercera parte de Conceptos espirituales, Lérida, 1612, fol. $69 \mathrm{v}^{\circ}$. Sobre el verso "los saca de dos en dos", cf. San Lucas, 10:1 "misit illos binos ante faciem suam"; y sobre el resto del epigrama, cf. San Juan, 21:21-22 (a continuación de una escena de pesca): "Hunc ergo [Ioannem] cum vidisset Petrus, dixit Iesu: Domine, hic autem quid? Dixit ei Iesus: Sic eum volo manere donee veniam, quid ad te?" -En sus Epigramas y hieroglificos, op. cit., fol. [27] $\mathbf{r}^{\circ}$, Ledesma reelabora esta composición para darle, como a todos los epigramas del librito, forma de décima. Se intitula "A San Iuan Evangelista en la Tina" ("ante portam Latinam", "en la Tina"; ¡milagro que a Ledesma se le haya escapado este juego de palabras!), y dice, esta vez sin glosas: "Preguntóle vn pescador / a su señor cierta vez: / ¿Qué se ha de hazer deste pez, / que me parece mayor? / Respondióle su señor: / Quiérole para guardar, / y siendo tal el manjar, / no ha de faltar, a fe mía, / quien en azeyte le fría / para que pueda durar".

48 Alonso De Ledesma, [Primera parte de] Conceptos espirituales, Madrid, 1600, fol. $131 \mathrm{r}^{\circ}$. En los Epigramas y hieroglificos hay, en cada página, una décima y una brevísima letra de tres versos con que se explica el jeroglífico. El jeroglífico de San Juan Evangelista es: "Pintóse vna lámpara ardiendo"; y la letra: "Apagar quiso su luz, / y como azeyte la echó, / nueuo resplandor la dio" (fol. [27] $\mathrm{r}^{\circ}$ ). - Estas letras son de una concisión extraordinaria. La del jeroglífico de la Coronación de espinas ("Pintóse vna granada abierta") es muy hermosa: "Fruta que rompe su pecho / y sus entrañas ofrece, / ser coronada merece" (fol. $14 \mathrm{r}^{\circ}$ ).

${ }^{40}$ [Primera parte de] Conceptos espirituales, fol. $132 \mathrm{r}^{\circ}$.

so Epigramas y hieroglificos, op. cit., fol. $37 \mathrm{r}^{\circ}$. (El relativo a Santo Domingo, en el fol. $\left.34 \mathrm{r}^{\circ}\right)$ 
reflejar ciertas ideas de los médicos de entonces, terriblemente recelosos en materia de higiene personal:

Aunque es peligroso el vaño que en la tina, luan, os days, como vos tan sano estáys, prouecho os haze y no daño ${ }^{51}$.

Medio siglo más tarde, un poeta de la academia del Conde de Lemos, Josef Navarro, volverá de nuevo al humor culinario en un villancico "A San Juan Evangelista":

$\ldots$..vnos vinagres sayones

lo echaron en el azeite.

Aunque el tirano enojado

anduvo astuto (a mi ver),

pues le pareció al malvado que estando el Santo mojado fuera fácil de torcer.

Mas con airados estremos

dixo: "Pues no te fatigas, aunque el azeite tenemos, no me parece que haremos

entre los dos buenas migas" 52 .

Otro excelente chiste culinario, referido a San Juan Bautista, encontramos en la extrañísima comedia de Damián Salucio del Poyo, Vida y muerte de Judas. Escena: el desierto; interlocutores: San Juan Bautista y dos ladrones, Dimas y Grismas [=Gestas], los mismos que a su debido tiempo serán crucificados con Cristo. San Juan predica penitencia; Dimas da muestras de su buen corazón; Grismas, en cambio, impaciente e iracundo, le grita al santo: “'Mas que os parta la cabeza!”, a lo cual replica él con exquisita mansedumbre:

-Ser mi cabeza partida

no puede, aunque yo quisiera, porque se ha de dar entera por postre de una comida 53 .

Esta clase de chistes ponía loco de entusiasmo a Gracián, el gran teorizador y loador de la agudeza, del equívoco, del "significar a dos luces". Entre los poetas más elogiados por él están justamente Ledesma y Cáncer. Del primero dice: "Son las obras del divino Ledesma un equívoco continuado; fue plausible en este genio, y quiso más ser el primero

51 Juan de LuQue, Divina poesia y varios conceptos [nótese esta palabra] a las fiestas principales del año, Lisboa, 1608, p. 74 .

52 Josef Navarro, Poesias varias, Zaragoza, 1654, pp. 112-113.

53 Citado por José Pío Tejera y R. DE MONCADA, Biblioteca del murciano, Madrid, 1924, p. 644. - No resisto a la tentación de citar otro buen chiste relativo a la muerte del Precursor de Cristo. Es de Gerónimo Cáncer y Velasco en una jácara "A San Juan Bautista", que termina: "...Y en medio de estas finezas / de santidad y de fe, / hay quien diga que le vio / muerto por una muger" (Obras varias poéticas, Madrid, 1761, p. 132) 
en él que segundo en otros". Y de Cáncer: "Oyeron una muí gustosa çampoña, mas por tener cáncer la Musa que la tocava, a cada concento se le equivocavan las vozes"54. También alaba Gracián la "grande sutileza" de Góngora, a propósito de un equívoco, muy en el gusto de Ledesma, que don Luis coloca en su romance a la beatificación de Santa Teresa de Ávila ${ }^{55}$. El chiste se basa en el nombre de Teresa de Cepeda y Ahumada y en el del obispo de Ávila, Alfonso Tostado de Madrigal, famoso por el volumen de sus escritos:

Tanto i tan bien escribió, que podrá correr parejas su espiritu con la pluma del Prelado de su Iglesia: pues Abulenses los dos, ia que no iguales en letras, en nombre iguales, él fue Tostado, Ahumada ella.

En el caso de San Lorenzo, la comicidad "culinaria" venía desde época muy remota. La célebre frase del mártir: Assum est, uersa et manduca, aparece ya en el De officiis de San Ambrosio ${ }^{56}$. El cordobés Pedro Clemente Negrete $\left(\dagger_{16} 6\right.$ o) la elabora simplemente en una Vida de $S$. Laurencio escrita en quintillas "joco-serias". El santo, una vez asado en la parrilla, sufre el martirio de los garfios:

$$
\begin{aligned}
& \text {...Las uñas de acero empuña } \\
& \text { la crueldad, rigor no chico, } \\
& \text { y el santo cuerpo razguña; } \\
& \text { y porque le juzgan rico, } \\
& \text { luego le meten la uña }
\end{aligned}
$$

Y Francisco Carrillo de Córdoba, en su Certamen histórico por la patria del exclarecido protomártir San Laurencio (Córdoba, 1673), nos asegura con la mayor seriedad del mundo que "en un libro manuscrito que se titula Academia espiritual", obra de insigne antigüedad (¡del año 1042, nada menos!) se leen los siguientes versos, francamente espantosos:

Hoy pone Dios en su mesa un fénix, vándalo asado, que después de estar quemado, la vida eterna interesa...

Aqueste fénix suave mucho gusto al cielo da, que como endiosado está, a todos a Dios les sabe ${ }^{58}$.

${ }^{64}$ Apud F. Lázaro Carreter, art. cit., p. $3^{67}$.

${ }_{55}$ Obras completas de Góngora, ed. cit., t. 2, p. 199. El elogio de Gracián, en la Agudeza y arte de ingenio, discurso xIV (Obras completas, ed. E. Correa Calderón, Madrid, 1944, p. 111a).

${ }_{58}$ Véase ErNst Robert Curtius, Literatura europea y Edad Media latina, México, 1955, Excurso IV ("Bromas y veras en la literatura medieval"), t. 2, pp. 605-606.

${ }_{57}$ Poesias de D." Pedro Clemente Negrete, ms. de la H. S. A. (se trata de una copia relativamente moderna).

${ }_{58}$ Cit. por Gallakdo, Ensayo, t. 2, col. 246. A. González Palencia y J. Hurtado, Hist. de la lit. esp., ed. cit., p. 538, copian los siguientes versos en honor de San Lo- 
El franciscano fray Damián Cornejo, autor de la voluminosa Chróntca seráphica, perpetró también no pocos villancicos "joco-serios" en honor de los santos de su orden, sobre todo San Francisco y San Diego de Alcalá. En un "Romanze" a este último hay algún eco remoto del chiste de los huevos. Le dice al santo que, por favor, sea bueno y no haga ya tanto milagro:

$$
\begin{aligned}
& \text {...A los pobrecillos ziegos } \\
& \text { que os vienen buscando a tientas, } \\
& \text { no sentándoles la mano } \\
& \text { les hagáis ver las estrellas }{ }^{59} \text {. }
\end{aligned}
$$

En unas "Quintillas" a Santa Clara, el eco es más preciso:

Oy mi deboción aclama, puesto que en estilo nuebo [!], a una virgen que fue dama de San Francisco, y se llama lo que no es yema en el huebo.

Su nombre es bien conozido, $y$ tanto en el mundo vale, que a mi me tiene aturdido ver que esté tan esparcido quien del cascarón no sale 60 .

En estos secuaces de Ledesma pensaba Polo de Medina cuando criticaba, no sin gracia, la epidemia villanciqueril. En la segunda de las Academias del jardin, el Licenciado "Pues sea" ha soltado un villancico estupendo en honor de San Sebastián:

-Si V.m. prosigue -dijo Jacinto-, ha de ser cosa de espanto.

-No me ha de quedar - respondió el Licenciado- santa ni santo en el cielo a quien no le haga una jacarandina a lo divino, con que pienso dejarme atrás a Cairasco con toda la millarada de sus otavas, que escribo yo más en una hora que el Tostado en toda su vida.

Y más adelante, en la academia cuarta, dice Don Juan:

...Pues vamos a las monjas con los villancicos. A sólo San Juan Bautista tengo hecho más de un siglo de coplas. Pues al Evangelista le tengo compuestas otras tantas. Pero digan: ¿me ha valido algo? iNi una rosquilla!61.

renzo como ejemplo de las "extravagancias" de Ledesma: "Seréis sabroso bocado / para la mesa de Dios, / pues sois crudo para vos / y para todos asado", y añaden: "Por extravios tan ridículos como irreverentes, la Inquisición prohibió uno de sus libros". Según parece, la Inquisición se alarmó también por algunos chistes demasiado irrespetuosos de Cáncer; hasta ahora, sin embargo, no he conseguido ver ninguna de las ediciones expurgadas. Sobre "La hostilidad contra los villancicos" véase el Estudio liminar de Alfonso Méndez Plancarte a las Obras completas de Sor Juana, t. 2, pp. liii-lix. Cf. también la censura de fray Pablo Yáñez de Avilés a las Obras lyricas [1720] de Francisco Antonio de Bances y Candamo, ed. F. Gutiérrez, Barcelona, 1949, pp. $40 \cdot 43$.

59 Obras poéticas M.S. del Rev." mo Padre Fr. Damián Cornejo, British Museum, ms. Eg. 1889 , fol. $54 \mathrm{v}^{\circ}$.

${ }_{60}$ Ibid., fol. $6_{5} \mathrm{v}^{\circ}$. - Característicamente frailuna es la mezcla de las ingeniosidades piadosas y de las obscenidades tontas. Véase, como ejemplo, el soneto "Ya no puedo vivir si no me capo" (ibid., fols. $17 \mathrm{v}^{\circ}-18 \mathrm{r}^{\circ}$ ); y también, los nauseabundos "Versos en ecos al desengaño del mundo" (fols. $32 \mathrm{r}^{0}-33 \mathrm{v}^{0}$ ). 
Lo cual nos proporciona un dato de interés acerca de la clientela de esa clase de composiciones.

Cerremos nuestro largo desfile con don Joseph Tafalla Negrete, "villanciquero" profesional como Vicente Sánchez, y aragonés como él. En su Ramillete poético hay sobre todo jácaras y jacarandinas y vejámenes y villancicos a los santos. Sólo en honor de Santo Domingo hay cinco romances y una poesía en quintillas. Tiene varias alusiones a la estrella, pero sin el chiste del huevo estrellado. Por ejemplo:

En el cielo de su frente luze vna estrella brillante. ¿Rara dicha! En fin, ay hombres que ya con su estrella nacen...

O este recuerdo del Polifemo de Góngora (“... de un ojo ilustra el orbe de su frente"):

Todo el orbe de su frente se iluminava de vn astro, que a tanto golpe de luzes, le dexó el rostro estrellado ${ }^{62}$.

Antonio Alatorre

El Colegio de México.

6. Salvador Jacinto Polo de Medina, Obras escogidas, ed. J. M. de Cossío, Madrid, 1931 (col. "Los clásicos olvidados"), pp. 164 y 221 . C.f. también, en el Hospital de incurables, la divertida requisitoria contra los que andan "trabucando las coplas de humano en divino" (ibid., pp. 313-314).

-2 Joseph Tafalla Negrete, Ramillete poético, Zaragoça, izo6 [ed. póstuma], pp. $244^{-2} 47$. 